\title{
Fellow or foe? Readers decide
}

\author{
Peter Anderson, MD, FRCSC
}

See related article on page 33

C ongratulations are due Dr. Grober and colleagues ${ }^{1}$ for shining a light on this important aspect of urological education, which clearly impacts all levels of training. The question is essentially whether the influence of fellows is for better or worse regarding residency training. The conclusions appear valid, with the caveat that the experience at a single educational institution may not be applicable to other centres. Since this report summarizes the results of a survey, the reader must also be cautioned not to assume that opinions equal facts. The responses summarized in Figures $2-12^{1}$ illustrate that reality is as variable as the number of lenses through which it is viewed. Illustrative of this phenomenon are responses to the question: "Are there too many fellows within the division?" Faculty stated "no"; fellows were politically neutral; and residents said "yes." I would be interested in the views of a fourth group: recently graduated residents who are currently in practice. They may have the most useful perspective, having no vested interest in the outcome of the survey and having access to the "retrospectoscope" (an imaginary device that allows perfect views of past events, R.D. Schwarz, personal communication, 2008) in formulating their responses.

Although I doubt that anyone would argue against the existence of subspecialty training, human nature may lead to the NIMBY response: "Not In My Back Yard." In the best interests of the health of both our patients and the specialty, we must resist the inclination toward NIMBY while also protecting the quality of all levels of training. This report takes a step in the right direction to achieve that goal.
Questions that will hopefully be addressed in future studies include assessment of possible regional or institutional differences, the views of program graduates (both fellows and residents) and subspecialty differences. The first conclusion listed by the authors: "program directors must clearly define the role of the fellow"1 is certainly the most important recommendation. The reader is left to draw his or her own conclusions concerning the central question: Fellow or foe?

From the Department of Urology, Dalhousie University, Halifax, NS

Competing interests: None declared.

\section{Reference}

1. Grober ED, Elterman DS, Jewett MAS. Fellow or foe: the impact of fellowship training programs on the education of Canadian urology residents. CUAJ 2008;2:33-7.

Correspondence: Dr. Peter A.M. Anderson, Professor of Urology, Dalhousie University, Halifax NS B3K 6R8; Peter.Anderson@iwk.nshealth.ca 